\title{
AN INTRODUCTION OF COMBINATIONS AND PERMUTATIONS WITH GOOGLE SPREADSHEET'S GOOGLE SCRIPT
}

\author{
Cathryn Van Landuyt, Missouri State University, U.S.A. \\ Jerry Chin, Missouri State University, U.S.A.
}

dx.doi.org/10.18374//JBR-20-3.3

\begin{abstract}
This paper demonstrates the use of Google script in connection Google sheets. Two example student level problems, combinations and permutations, are presented. The example problems are presented with Google script code provided along with the underlying rationale. The code was developed on a Chromebook. The emphasis is on code, which is based on JavaScript and in some instances, specific to the Chromebook sheets environment.
\end{abstract}

Keywords: Spreadsheets, Google script, Code, Chromebook, JavaScript, Combinations, Permutations 